\title{
O planejamento estratégico municipal como instrumento de gestão em cenários complexos: um estudo sobre os condicionantes dos planos da Cidade de Barcelona*.
}

\author{
The municipal strategic planning as a management tool in complex scenarios: \\ a study on the conditions of the plans of the Barcelona City
}

Janaína de Mendonça Fernandes ${ }^{1}$

Resumo:

O presente trabalho é um estudo exploratório sobre os condicionantes que permitiram a adoção e a perpetuação do processo de planificação da cidade de Barcelona. Foram verificados os condicionantes políticos, históricos e sociais, como também a gestão de políticas públicas. Esta pesquisa teve por objetivo observar se os referidos condicionantes foram determinantes para a aplicação do método de planificação na capital catalã, tendo em vista a difusão de seu modelo de planejamento em todo mundo, principalmente na América Latina. Dentro desta análise, procurou-se considerar o que sustentou ao longo do tempo o seu planejamento e de que forma este se configurou. Para tal, utilizaram-se pesquisas documental e bibliográfica, e conjuntamente entrevistas em profundidade semi-estrutradas com diferentes agentes partícipes do plano. $O$ material foi analisado por meio da técnica de análise de conteúdo, concluindo-se que o condicionante mais influenciador para a adoção e perpetuação do método de planificação em Barcelona foi o condicionante institucional, isso porque, ao longo do tempo, a região em questão desenvolveu instituições que são capazes de levar adiante políticas públicas de longo prazo. Assim sendo, para a aplicação da metodologia de planificação de Barcelona em outras regiões seriam necessárias adaptações.

Palavras-chave: planejamento estratégico; gestão de cidades; administração municipal

Abstract:

This work is an exploratory study on the conditions that led to the adoption and perpetuation of the planning process of the city of Barcelona. We checked the political, historical and social constraints as well as the management of public policies. This study aimed to observe if those conditions were crucial for the application of the method of planning in the Catalan capital with a view to disseminating its model of planning worldwide, mostly in Latin America. Within this analysis, it was considered what supported the planning of the city of Barcelona over time and the way it was set up. For this purpose, documentary and bibliographic research were made, as well as semi-structured in-depth interviews with different players that are involved with the plan. The data were analyzed through the technique of content analysis, concluding that the most influencing constraint for adoption and perpetuation of the method of planning in Barcelona was the institutional constraint, because, throughout time, the region in question developed institutions that are able to carry out public policies for the long term. Thus, applying Barcelona's methodology of planning in other regions would require some adjustments.

Keywords: strategic planning, cities management, municipal administration

\footnotetext{
${ }^{1}$ Doutora em Administração pela Escola Brasileira de Administração Pública da Fundação Getulio Vargas - EBAPE/FGV. Consultora Técnica de Projetos na Fundação Getulio Vargas/Projetos. Endereço: Praia de Botafogo, 190 - $6^{\circ}$ andar - Botafogo - Rio de Janeiro RJ - Brasil - CEP 22253-900. E-mail: janaina.fernandes@fgv.br

Artigo submetido em setembro e aceito em novembro de 2008
} 


\section{Introdução:}

Toda metrópole é um cenário complexo. Cada uma possui sua dinâmica própria e particular, que vai além da interação das pessoas com o espaço urbano. Essa dinâmica é marcada pelo desenho de seus espaços, pela sua história, pelas relações econômicas, sociais e culturais nestes espaços desenvolvidas. Os espaços moldam as relações presentes neles da mesma forma que são moldados pelas relações. Visto desta forma, a administração de uma cidade ganha um papel primordial neste cenário complexo, o papel de planejar e intervir nestes espaços para que estas interações se dêem da melhor forma possível.

Em adição a esta complexidade já presente nessas grandes metrópoles, nas décadas de 70 e 80, com a crise nas cidades industriais e o advento da globalização, esses espaços passam a se configurar como centro de negócios e lócus privilegiado do capital transnacional. Assim sendo, a administração dessas cidades, seus cenários urbanos e conseqüentemente seus espaços, se tornam cada vez mais complexos. Esses centros urbanos foram designados por alguns autores como cidades globais, e possuem características similares. Algumas linhas de pesquisa acreditam que é possível reproduzir estas experiências por meio do planejamento estratégico, que surge como resposta à crise do antigo padrão de planejamento urbano.

Assim, o presente trabalho diz respeito à questão urbana, procurando observar quais os condicionantes que levam à adoção e a perpetuação do processo de planificação da cidade de Barcelona, sob a perspectiva da administração pública, acessando elementos do urbanismo, da sociologia, da política e da administração. Por se tratar de um estudo exploratório, de acordo com Vergara (2005), não houve hipóteses previamente delineadas.

Teve-se como objetivo principal analisar os mecanismos de gestão dos planejamentos estratégicos da experiência de Barcelona, verificando quais os condicionantes que permitiram a adoção e a perpetuação do método de planificação na referida cidade.

Além disso, a relevância deste estudo se mostra face à disseminação da metodologia de planificação elaborada dentro do contexto do Planejamento Estratégico de Barcelona como instrumento de gestão de cidades em diferentes partes do mundo, com o incentivo e difusão de diversas agências multilaterais, como o Banco Internacional de Desenvolvimento (BID). Contudo, para replicar uma metodologia de planejamento estratégico em contextos diferentes, torna-se necessária uma avaliação profunda dos condicionantes que propiciaram a adoção e a perpetuação desta metodologia ao longo do tempo, e se esses condicionantes que propiciaram esta adoção são determinantes para a sua aplicação e perpetuação. Assim sendo, a justificativa desta pesquisa fundamenta-se a partir do momento em que tais condicionantes são determinantes para a aplicação do método, tornando-se necessárias adaptações para aplicação em outras localidades. Por isso, a pesquisa é imprescindível para saber se os condicionantes são determinantes ou não.

Ao iniciar a pesquisa sobre a cidade de Barcelona, um cenário complexo se apresentou: Há uma história que se destaca pelo sentimento de nação presente na Catalunha, que pode ter influenciado uma tradição de planificação continuada; uma estrutura administrativa municipal e regional; e também um cenário político estável. Todos esses fatores dão suporte à metodologia de planejamento estratégico delineado nos planos estratégicos de Barcelona e que propiciaram o salto de escala dado do terceiro plano (municipal) para o quarto plano (metropolitano). Além disso, deve-se considerar a capacidade dos gestores em negociar e a janela de oportunidade aberta pelas Olimpíadas de 1992.

Como se pôde notar durante a pesquisa, muitos fatores, além da globalização, influenciaram direta e indiretamente no contexto onde os planos estratégicos de Barcelona estão inseridos. Esses fatores apresentamse no decorrer do artigo divididos em quatro partes. Na primeira parte, são descritos os contextos nos quais estão inseridos os planos estratégicos da cidade de Barcelona: o histórico, o administrativo e o político, além das teorias utilizadas para proceder as suas análises. Na segunda parte, apresentou-se a metodologia; análise de conteúdo; a coleta dos dados; doze entrevistas em profundidade com agentes diretamente envolvidos no processo de planificação; e a análise dos dados, feita com o auxílio do software ATLAS Ti. Na terceira e última 
parte, apresenta-se a conclusão do trabalho, na qual se observa que o condicionante que mais impactou a adoção e a perpetuação do processo de planificação da cidade de Barcelona foi o condicionante institucional.

\section{Os Contextos Histórico, Político e Administrativo de Barcelona:}

Nesta parte do artigo apresentam-se os contextos histórico, político e administrativo onde se insere o processo de planificação da cidade de Barcelona e de sua região metropolitana e as teorias que auxiliaram a análise realizada. Para melhor entendimento do processo como um todo, optou-se por discutir a teoria em conjunto com a apresentação dos referidos contextos, o que permite a apreciação direta da análise teórica no processo de planificação catalão.

\section{O Condicionante Histórico:}

Por vários séculos, a Catalunha passou por um processo de recuperação e de valorização de suas raízes, tornando a região diferente do restante da Espanha e, a partir da metade do século XIX, a Catalunha se organiza em torno de um projeto político com objetivo de solidificar sua identidade regional própria. Esse processo foi acompanhado por um crescente desenvolvimento econômico evidente desde o início do século XX (GENERALITAT DE CATALUNHA, 2007).

Este desenvolvimento se estende até a Guerra Civil de 1936, que instituiu 40 anos de ditadura. Durante o período da ditadura, novamente, a Catalunha volta a ter sua autonomia reduzida, sua língua proibida e sua identidade cultural perseguida por Franco e seus seguidores. Isso só foi mudar depois de 40 anos, quando a democracia é restabelecida com a promulgação da Constituição espanhola de 1978 (GENERALITAT DE CATALUNHA, 2007).

Entretanto, uma questão torna a região da Catalunha diferente das demais, a configuração atual do poder político na Catalunha não é definida na constituição de 1978, mas sim no Estatuto da Autonomia de 1977. Diferentemente das outras instituições autônomas do Estado espanhol, a Generalitat da Catalunha foi restabelecida no ano de 1977, antes da promulgação da Constituição de 1978. Isso porque a Generalitat da Catalunha já existia na Espanha aproximadamente há 700 anos, na figura do organismo executivo criado pelas Cortes Gerais da Confederação da coroa catalano-aragonesa (GENERALITAT DE CATALUNHA, 2007).

Assim sendo, o fato de a Catalunha ser uma região independente com instituições autônomas desde o século X e ter sempre lutado para manter sua autonomia, mesmo durante a ditadura, faz com que, de alguma forma, seu processo histórico gere o que Peter Evans (1997) define como dotes socioculturais. Esses dotes se constituem por meio do exercício democrático e do associativismo ao longo do tempo, e contribuem para a formação de um estoque de capital social acumulado durante o processo histórico. Contudo, segundo o mesmo autor, não são apenas os dotes socioculturais que são capazes de formar a base para a criação de capital social, a sinergia entre Estado e sociedade também forma estas bases.

Além disso, em relação à região metropolitana de Barcelona, há mais de 50 anos que existem instituições de caráter metropolitano, o que demonstra uma tradição destes municípios em planificar conjuntamente. Logo, os agentes presentes na dada região de alguma forma já estavam concertados dentro destas entidades, o que pode ter facilitado o salto de escala dado do terceiro plano estratégico de Barcelona, um plano municipal, para o quarto plano estratégico de Barcelona, um plano metropolitano que engloba os 36 municípios da AMB (Área Metropolitana de Barcelona). Esse forte associativismo de alguma forma acaba também corroborando a existência dos dotes socioculturais delineados dentro da teoria de Evans (1997). Isso porque, na Catalunha, o exercício democrático e o associativismo, ao longo do tempo, constituíram um estoque de capital social acumulado durante o processo histórico. Essas bases para construção de capital social, existentes devido a esses dotes socioculturais que surgiram ao longo do tempo, por meio do exercício cívico e do forte associativismo, 
fazem com que os governos tenham um melhor desempenho, por meio da sinergia Estado - Sociedade (Evans, 1997).

A história pode ter facilitado a implementação da metodologia dos planos estratégicos de Barcelona, mas ela por si só não explica todo processo ocorrido que culminou na implementação e continuidade dos referidos planos. Parte da explicação pode estar contida também na reforma administrativa elaborada pela prefeitura e que teve início em 1979. A referida reforma será analisada mais detalhadamente no próximo seguimento deste artigo. Além disso, o cenário político catalão, que propiciou a reforma, também pode ter tido impacto na decisão de iniciar e perpetuar o processo de planificação da cidade.

Assim, se elencam mais dois condicionantes para a adoção e perpetuação do método de planificação na cidade de Barcelona - a reforma administrativa municipal e o cenário político ao qual a prefeitura se inseria - , que, conjugados à história da cidade, podem ter dado suporte para os mecanismos institucionais do plano estratégico municipal, fazendo com que seus agentes se ajustassem, dando assim continuidade e capilaridade ao processo de planificação da cidade. E é sobre esses dois condicionantes, o administrativo e o político, que se discutirá adiante.

\section{O Condicionante Institucional:}

Subirats (1989) relata que os efeitos da crise dos anos 70 e os seus reflexos em todo mundo fizeram com que muitos governos reestruturassem a administração pública, incrementando a capacidade de resposta aos anseios de grupos de interesse que pressionavam o governo em busca de políticas públicas para atender suas demandas. Foi o que ocorreu na Espanha, na década de 70, quando uma profunda crise acabou estimulando o governo deste país a buscar novas soluções. Neste sentido, o governo espanhol, ao executar suas ações, focou reformas administrativas que incrementassem sua eficácia, discutindo os critérios que tornam os problemas prioritários. Assim sendo, a administração pública do referido país passou a analisar quais objetivos traçar para alcançar os resultados previstos dentro de um governo com fortes restrições orçamentárias. Isso porque a incapacidade da administração pública em continuar a assumir o crescimento da máquina estatal contribuiu para a necessidade de se redefinir o que é público e privado. Essa discussão teve como pano de fundo as restrições financeiras que se impunham em relação à eficácia dos serviços prestados.

Logo, na Espanha, essas preocupações impactaram a estrutura da administração pública em seus diferentes níveis. Em primeiro lugar, a reestruturação passou por redirecionar o enfoque dos estudos sobre administração pública, que deixaram de ser centrados na legitimidade de suas ações, passando a uma perspectiva voltada para os resultados de suas atuações e das técnicas de análise que permitam melhorá-las. Não que a legitimidade deixa de ser importante, apenas o foco dos estudos é deslocado (SUBIRATS, 1989).

Este novo foco poderia tornar mais plausível o trabalho descritivo da realidade política e administrativa ao qual a política pública irá ser elaborada, implementada e desenvolvida, tornando mais fácil dar continuidade aos programas da administração pública. Mas, sobretudo, com este processo descritivo, este novo foco pode tornar mais eficiente e eficaz as referidas políticas públicas. Contudo, o mesmo autor destaca que a natureza da administração pública não permite a aplicação direta de técnicas generalizadas provenientes do ambiente privado, o mais correto seria, portanto, a combinação entre uma mentalidade de melhora da gestão e as particularidades do setor público (SUBIRATS, 1989). Para aplicação destas diretrizes propostas por Subirats (1989), o primeiro passo seria definir o problema de forma que se possa pôr em marcha uma política pública. Sem a definição clara de um problema não há como se postular visões do mesmo ligadas a soluções.

Em Barcelona não foi diferente. Em 1979, a prefeitura da cidade de Barcelona se encontrava em uma profunda crise. O problema definido pela prefeitura para ser enfrentado foi o fato da administração pública local não conseguir responder às demandas da cidade e de seus cidadãos. Para se dar conta dessa questão, iniciou-se uma reforma administrativa, nos moldes propostos por Subirats (1989). Esta reforma tinha o intuito de pôr ordem à máquina Estatal da administração municipal e impulsionar políticas que dessem respostas às múltiplas 
demandas sociais, e foi feita em dois movimentos de reestruturação. $\mathrm{O}$ rigor e a formalidade administrativa marcaram esse primeiro movimento de reestruturação da prefeitura, em que a base da administração local foi organizada e assentada para posteriormente iniciar o segundo movimento de mudança, o chamado movimento transformador. $\mathrm{O}$ segundo movimento de mudança teve início em um novo mandato municipal e voltou seu foco para a eficácia do funcionamento da prefeitura (AJUNTAMENT DE BARCELONA, 1999).

Mediante a esta a nova perspectiva, a capacidade de inovação dos poderes públicos para enfrentar as novas necessidades passa a ser uma condição importante para se estruturar políticas públicas e desenvolver programas de atuação com continuidade. A sucessão e a finalização de políticas públicas se tornam um ponto chave em momentos muito relevantes para a estrutura da administração pública, por conta das questões ligadas ao conhecimento e à resistência a mudanças de toda organização burocrática. Assim sendo, a agenda de mudanças na administração da cidade de Barcelona teve continuidade e um segundo movimento de mudanças, o movimento de transformação, que teve início na década de 90, tendo seu ponto máximo no ano de 1992, anos dos Jogos Olímpicos (AJUNTAMENT DE BARCELONA, 1999).

Assim, o modelo de análise de políticas públicas, na perspectiva de Subirats (1989), além de se encaixar nas medidas adotadas pelo município de Barcelona para solucionar a crise a qual a administração pública enfrentava, parece servir como base de análise para a estruturação da cidade para sediar os Jogos Olímpicos de 92 e, posteriormente, para explicar a decisão da prefeitura em manter o nível de investimentos elevados para que a cidade continuasse crescendo após as Olimpíadas. Além disso, no caso de Barcelona, houve o protagonismo da iniciativa pública frente à liderança da estruturação da cidade em torno dos jogos e na busca da eficiência pelo setor público frente ao grande consenso social e político do momento (MONCLÚS, 2003).

Logo, com base no que foi delineado, pode-se observar que na formação da agenda política diferentes fatores interferem desde a elaboração do problema até a esfera decisória da política pública elaborada para solucionálo, se perpetuando em sua implementação. Assim, uma vez definido o problema e assumida a condição de problema a ser resolvido pelo poder público, é necessário seguir adiante traçando as diferentes alternativas de ação (SUBIRATS, 1989). Foi o que aconteceu na década de 90 na cidade de Barcelona, onde o modelo gerencial desenvolvido pela prefeitura da cidade tomou impulso. Sendo que até o ano de 1992, anos dos Jogos Olímpicos, o esforço de investimento foi muito grande. Era necessário transformar Barcelona não apenas para as Olimpíadas, mas também para responder ao déficit histórico de demandas de infra-estrutura e dos cidadãos (AJUNTAMENT DE BARCELONA, 1999). Para responder a este déficit, e ao mesmo tempo manter o nível de crescimento na cidade após a realização dos Jogos Olímpicos (problema elencado pelo primeiro plano estratégico da cidade), a agenda da prefeitura foi alterada em torno de um processo de planificação continuado, decisão que vai ao encontro da elaboração e implementação do primeiro plano estratégico da cidade.

Assim, os Jogos Olímpicos mudaram profundamente a cidade, foram produzidos incrementos significativos atrelados à decisão de se intensificar os ingressos fiscais. Era prioritário otimizar recursos, racionalizar a organização governamental e sua gestão, além de melhorar os serviços prestados aos cidadãos. O objetivo central era o de desenhar políticas que permitiram incrementar os investimentos na cidade (AJUNTAMENT DE BARCELONA, 1999). Assim sendo, antes dos Jogos Olímpicos se realizarem, algumas diretrizes administravas foram tomadas e, a partir do ano de 1991 o governo municipal inicia uma política de contenção de despesas e de modernização administrativa. A partir deste ponto, apostou-se em aprofundar o processo de gerenciamento no sentido de enfatizar os critérios de gestão em todos os setores e distritos da administração municipal (AJUNTAMENT DE BARCELONA, 1999).

Após essas reformas, especialmente após o ano de 1992, segundo Marshall (2000), Barcelona tornou-se conhecida na Europa por seus ambiciosos programas de planejamento urbano realizados sob a liderança do município. Alguns autores defendem que o "modelo Barcelona" de planejamento emergiu desta experiência, conjuntamente a uma abordagem distinta para governança urbana, sendo que este princípio aplica-se particularmente ao período posterior às olimpíadas (MARSHALL, 2000). 
Esta busca da prefeitura de Barcelona pela adaptação da cidade a esta nova realidade ligada à globalização, e paralelamente a isto pela qualidade dos serviços, assim como às reformas empreendidas em sua gestão e implementadas desde os anos 70, faz com que seja possível traçar um paralelo destes processos com a metodologia de planificação de Barcelona que vá ao encontro da teoria desenvolvida por Skocpol, Evans e Rueschmeyer (1985). Esses autores, por meio de seu trabalho, repensam o papel do Estado em relação à economia e a sociedade, considerando este Estado como um agente independente e autônomo. Para Sckocpol (1985), um Estado autônomo e independente é concebido como uma organização que formula e busca alcançar metas que não apenas reflitam os interesses da sociedade, de uma classe ou de um grupo.

A perspectiva de Evans e seus colaboradores (1995), tomando como base o estudo de diversos países em desenvolvimento, tem como eixo a idéia de que as instituições têm um papel primordial na formação do capital social. Assim, de acordo com o referido autor, para que as instituições do Estado funcionem bem, é necessário que haja uma sinergia entre o Estado e a sociedade civil na implantação de políticas para o desenvolvimento social. A abordagem desenvolvida por Evans (1995) tem como eixo a autonomia do Estado, autonomia exercida e construída pela prefeitura da capital catalã.

Além disso, conforme ressaltado anteriormente, de acordo com a mesma chave analítica, alguns locais possuem os chamados dotes socioculturais que auxiliam na construção desta sinergia. Mas, independente destes dotes, para o autor é possível promover as bases para construção de capital social por meio da sinergia Estado e sociedade, promovendo-se políticas participativas.

Assim, Evans (1995) desenvolve o conceito de autonomia inserida (embedded autonomy), que vê o Estado como agente na elaboração e implementação de políticas públicas em uma combinação da burocracia conectada fortemente com a estrutura social que a cerca. Com isso, o Estado estará dotado de autonomia, pois, irá exercer sua autoridade por meio de um aparato burocrático sólido (autonomy) ao mesmo tempo em que irá se inserir (embeddedness) no setor privado, estabelecendo laços de confiança que irão propiciar a cooperação para atingir seus objetivos. Segundo a tese de Evans (1995), o governo tem uma importância primordial na indução do bom funcionamento das instituições do Estado, o que se dá por meio da elaboração de políticas públicas com participação, interação entre o Estado e sociedade. Tendo o Estado uma boa autonomia e agindo combinadamente com a sociedade civil organizada, pode-se: ampliar a democracia, tornar políticas públicas mais eficientes e responsáveis, além de reformar as instituições públicas e ampliar as dotações latentes sociais. Resumindo, um Estado com instituições fortes é um Estado autônomo, isto é, um Estado que tem um corpo burocrático que não pode ser atingido, este corpo garante sua autonomia, que é definida como a capacidade do Estado em adotar políticas, mesmo sendo contrárias a certos grupos de interesse. No entanto, esse mesmo Estado deve aumentar a capacidade de participação da sociedade civil, não devendo ver a sociedade como cliente, mas sim como partícipe importante na formulação das agendas governamentais (EVANS, 1995).

Essa perspectiva adéqua-se à Barcelona, onde a cidade passou a enfatizar o papel da prefeitura não mais como um operador executivo, mas como um catalisador dos diferentes agentes presentes na cidade, fortalecendo a administração pública e sua burocracia neste sentido (AJUNTAMENT DE BARCELONA, 1999). Assim, em tese, o modelo criado dentro da administração municipal de Barcelona buscou evitar disfunções geradas pelas interferências da política nas tarefas ligadas à burocracia da administração municipal, fortalecendo a burocracia e as instituições municipais, como defende a teoria de Evans (1995). Dentro desta estrutura, os Conselheiros Eleitos (Consejales Electos), os vereadores, se tornariam o elo principal de interlocução com a sociedade, dependendo deles as decisões políticas e o controle (fiscalização) dos resultados da política municipal, desvinculando da função os vereadores da gestão e a burocracia municipal (AJUNTAMENT DE BARCELONA, 1999).

Paralelo a isto, a administração da prefeitura, em sua parte burocrática, necessitava se apoiar e se adaptar à dimensão política do governo da cidade, para que a burocracia ganhasse força e articulação com as decisões de cunho político. Em tese, tratava-se de deixar as tarefas administrativas quotidianas, a obtenção de resultados 
que cumpram as decisões políticas e o desenvolvimento de programas de atuação politicamente pactuados, a cargo dos burocratas de carreira. Assim, as funções exercidas pelos representantes eleitos, teoricamente, não entrariam em conflito com as dos burocratas de carreira (AJUNTAMENT DE BARCELONA, 1999). Com isto, Barcelona estruturou a administração do município sobre dois eixos: $\mathrm{O}$ eixo da gestão, que envolve a execução e a gestão das políticas públicas, que ficou sob a responsabilidade dos burocratas de carreira, e o eixo da política, que envolve as questões ligadas ao governo e aos órgãos de controle e que abrange as funções dos políticos eleitos (AJUNTAMENT DE BARCELONA, 1999).

A função principal da administração municipal da cidade de Barcelona passa a ser definida como a de impulsionar, incentivar e liderar iniciativas para prestação de serviços para a cidade, o que exige delinear estratégias e planos, ao invés de atuar como prestadora de serviços básicos. Em tese, a administração municipal passaria apenas a garantir a adequada prestação de alguns serviços urbanos e buscar a almejada disciplina urbana. A prefeitura passa a realizar o que ela mesma denomina como "construir a cidade" sobre as bases e com a colaboração dos agentes urbanos que incluem uma gama ampla e plural de instituições púbicas e privadas. O objetivo era o de definir denominações comuns, áreas de consenso para facilitar iniciativas supostamente em favor da cidade (AJUNTAMENT DE BARCELONA, 1999).

Além disso, deve-se destacar no processo catalão o que Evans (1995) define como construtibilidade, que busca explicar que a sinergia não é apenas dependente dos chamados dotes socioculturais, que são formados ao longo do tempo por um processo histórico que formam capital social. A construtibilidade pode ser induzida por arranjos institucionais, isto é, pela construção e implementação de políticas públicas baseadas na participação. Essas políticas públicas baseadas na participação geram assim as bases para a construção de capital social, impactando positivamente o Estado. Assim, em tese, o Estado passaria a funcionar melhor por conta da sinergia Estado - Sociedade induzida por políticas participativas.

No caso de Barcelona, a sinergia se dá tanto pela existência da chamada construtibilidade como pelos dotes socioculturais, como observado no início deste artigo. A construtibilidade é definida por Evans (1997) como um processo possível na maior parte dos contextos e que pode ser alcançado por meio de políticas públicas baseadas na participação, o que ao longo do tempo gerariam as bases para construção de capital social. Essa construtibilidade se realizaria em Barcelona pela busca da prefeitura em realizar o que ela mesma denomina como "construir a cidade" sobre as bases e com a colaboração dos agentes urbanos. Assim como, pelo foco dado a políticas participativas, fato que pode ser observado dentro da reforma administrativa da prefeitura, quando, em 1996, a participação adquire um papel fundamental na gestão da cidade e os mecanismos participativos e os espaços de diálogo com a cidade são reforçados.

Este novo direcionamento dentro da administração pública municipal, de alguma forma deu impulso à implementação e continuidade do processo de planificação da cidade. Isso porque paralelamente à reforma administrativa da prefeitura de Barcelona, em 1990, o Primeiro Plano Estratégico foi delineado com objetivos muito próximos à reforma em curso (ASSOCIACIÓ PLA ESTRATÉGIC BARCELONA 2000, 2003). Além disso, seguindo os moldes da sinergia que se dá por meio da construtibilidade (EVANS, 1997), assim como a reforma administrativa, a metodologia do plano estratégico também se configura como um processo participativo que busca criar consenso entre os diferentes agentes urbanos a respeito do futuro da cidade.

Além disso, a administração local traça um problema que ganha força e passa a nortear a política a ser implementada: Como manter o nível de investimentos elevados após a realização dos jogos e, assim, garantir o crescimento da cidade de Barcelona? O caminho para a solução deste problema vai ao encontro da teoria desenvolvida por Subirats (1989). Isso porque, como já ressaltado anteriormente, a finalidade do primeiro Plano Estratégico Econômico e Social, Barcelona 2000, era dar continuidade ao dinamismo e ao impulso econômicos gerados pelos Jogos Olímpicos. Para tanto, foi produzido um marco de reflexão, o diagnóstico da cidade, onde foi estabelecido um programa de atuação e de geração de consenso a médio e longo prazos, em torno de um ideal de cidade a ser alcançado. A prefeitura de Barcelona era a instituição promotora deste marco 
de reflexão. Contudo, um dos objetivos a ser atingido era o denominado protagonismo da cidade no Plano, isto é, a participação dos diferentes agentes sociais e econômicos presentes em Barcelona. Em tese, por meio desta participação, a geração de consenso se tornaria mais fácil (AJUNTAMENT DE BARCELONA, 1999).

Neste sentido, a metodologia dos planos estratégicos de Barcelona tenta corroborar esta articulação política e administrativa delineada pela prefeitura em sua reforma administrativa, assim como a tentativa de sinergia definida por Evans (1997). Isso porque a referida metodologia é definida como participativa onde as diferentes instâncias do plano, como o Conselho Geral do Plano Estratégico (Consejo Gaeneral del Plan Estratégico) e o Comitê Executivo do Plano (Comité Ejecutivo), há a participação dos denominados agentes urbanos de Barcelona, assim como da Prefeitura da cidade. Contudo, o contexto político também deve ser levado em conta, conforme defende Evans (1997).

Assim, observando o ponto de vista defendido por Evans (1997), em que a sinergia não depende apenas dos chamados dotes socioculturais, podendo ser construída por arranjos institucionais entre o Estado e Sociedade por meio de políticas participativas, as tentativas de sinergia podem ou não dar certo, sendo primordial neste processo o contexto político como fator no sucesso das referidas tentativas. Logo, a premissa mínima para facilitar a sinergia é o contexto político. Tendo o setor público, que incorporar a construção cívica como parte de sua missão (EVANS, 1997).

Tendo isto como base, nas próximas páginas, será discutido mais um condicionante para a adoção e perpetuação do processo de planificação da cidade de Barcelona, seu contexto político. Contexto este que pode ter influenciado a implementação e a sustentação do tempo dos planos estratégicos da referida cidade.

\section{O Condicionante Político:}

É na primeira metade da década de 80, quando começam a se esboçar as mudanças pelas quais fizeram com que surgisse o chamado método de planificação de Barcelona. É importante entender essas mudanças dentro de um novo paradigma do urbanismo que despontava em escala internacional. Essas mudanças substantivas estavam associadas à desaceleração do crescimento demográfico e urbano que se observa nas cidades européias, à crise econômica dos anos 70 e início dos 80 e aos movimentos que questionam o planejamento convencional e o urbanismo funcionalista. Mas, no caso de Barcelona, especificamente, é importante entender também sua conjuntura especial e fazem parte desta conjuntura as alterações políticas pelas quais passavam a Espanha, em especial a redemocratização do país e a reestruturação do Estado em torno da eficácia de suas ações (MOCLÚS, 2003).

Além disso, segundo Subirats (1989), não se pode supor que a implantação de qualquer técnica de gestão irá suplantar a capacidade de decisão das pessoas constitucionalmente eleitas para exercer cargos públicos. Logo, a análise do contexto político ao qual a administração pública da cidade de Barcelona está inserido é um fator primordial para compreensão de sua reforma gerencial. Assim como, para se analisar a implementação e a continuidade de seus Planos Estratégicos. Isso porque, este contexto, em tese, pode ter um impacto direto na sustentabilidade do processo de planificação da capital da Catalunha.

Os municípios, segundo o artigo 140 da constituição espanhola, têm a sua autonomia garantida, gozam de personalidade jurídica plena e são governados e administrados pelos seus Ayutamientos (Prefeituras) que são governados por seus Alcaldes (Prefeitos) e Consejales (Vereadores). As eleições destes Consejales são feitas por meio de sufrágio universal, em listas fechadas e apresentadas pelos partidos, isto é, se vota no partido de preferência. Já o prefeito, de acordo com o capítulo IX, artigo 196 da lei orgânica 5/1985, que estabelece o regime eleitoral espanhol, é eleito pelos Consejales. Podem ser candidatos todos os Consejales que encabeçam a lista das candidaturas dos partidos eleitos. Em se obtendo a maioria absoluta dos votos do Consejo, o candidato é eleito Alcalde. Caso isso não ocorra, é proclamado Alcalde aquele que encabeça a lista do partido que obteve mais votos populares em todo município (ESPANHA, 1985). É bom lembrar que, na Espanha, escolhem-se nas eleições os partidos de preferência e não os candidatos deste partido. Os candidatos são 
apresentados em uma lista fechada ordenada pelo partido. Após a distribuição dos pontos por partidos, verificase a ordem da lista de cada candidatura e as cadeiras são atribuídas aos candidatos do partido de acordo com esta ordem (ESPANHA, 1985).

Este sistema eleitoral teve um impacto na configuração do cenário político da cidade de Barcelona e conseqüentemente na constituição de seus planos estratégicos. Graças a este sistema, a elaboração de estratégias para a cidade poderia ser pensada dentro de um horizonte de tempo maior que um mandato. Isso porque não há limite de perpetuação no poder, desde que se tenha a maioria dos votos e conseqüentemente a maioria das cadeiras no conselho, há uma estabilidade política maior devido à fidelidade partidária e ao sistema eleitoral parlamentarista. É assim que o PSC (Partit dels Socialistes de Catalunya) está no poder desde 1979. Mesmo havendo eleições de quatro em quatro anos, houve poucas trocas de prefeitos durante todo o período analisado (AJUNTAMENT DE BARCELONA, 1999).

Assim, apesar das eleições municipais, na Espanha, ocorrerem de quatro em quatro anos, o PSC (Partit dels Socialistes de Catalunya) está no poder na cidade de Barcelona desde 1979. O primeiro prefeito representado do partido eleito, em 1979, foi Narcís Serra, que saiu do cargo em 1982 para assumir o ministério de Defesa no governo de Felipe Gonzáles, na época presidente da Espanha. Narcís Serra apontou como seu sucessor Pasqual Maragall, que teve seu mandato confirmado nas eleições municipais de 1983. Pasqual Maragall fica no cargo até 1997, quando sai da prefeitura para se candidatar e se eleger como Presidente de la Generalitat (governador da Catalunha), apontando para seu lugar Joan Clos (AJUNTAMENT DE BARCELONA, 2007).

Joan Clos assumiu em 1997, tendo seu mandado confirmado nas eleições de 1999, mantendo-se no cargo até setembro de 2006, quando deixou o posto para assumir o Ministério de Indústria, Comércio e Turismo no governo de José Luis Rodríguez Zapatero, atual Presidente da Espanha. Joan Clos indicou para seu lugar como Alcalde Jordi Hereu, também do PSC, que teve seu mandato confirmado nas eleições de 2007 (AJUNTAMENT DE BARCELONA, 2007). Logo, o sistema eleitoral e estabilidade política por ele proporcionada podem ter relação com a constituição dos Planos Estratégicos da cidade de Barcelona. Isso porque a estabilidade nas resultantes do processo político pode ter facilitado a continuidade do processo de desenvolvimento da planificação da cidade, e sua constituição como município central de uma região metropolitana integrada por um sistema regional metropolitano.

Assim, a transformação da cidade teve seu ápice em 1992, com a realização dos Jogos Olímpicos de Barcelona, e os fortes investimentos em infra-estrutura entre os anos de 1987 e 1992. O PSC já estava há treze anos no poder e, com isso, pôde proceder à reforma administrativa da prefeitura, assim como dar início e continuidade ao processo de planificação da cidade, já que o Primeiro Plano Estratégico da cidade de Barcelona data de 1990 , alavancando assim a transformação urbana.

Entretanto, antes da referida transformação, havia no governo a denominada "consciência de crise", que, segundo Borja (1995), se refletia na degradação do centro histórico da cidade e no crescimento desordenado do centro moderno, processos que impactavam de forma negativa os cidadãos e os agentes urbanos. Nos bairros populares, era necessário atender a diferentes demandas sociais que surgiram com a longa falta de investimentos durante o período ditatorial. Com o advento da democracia e as primeiras eleições locais livres em 1979, era necessário dar respostas às demandas reprimidas. Neste sentido, a perpetuação do PSC no poder facilitou o desenvolvimento da reforma administrativa da prefeitura e da estruturação dos planos estratégicos da cidade.

Assim, de acordo com Borja (1995), a velocidade da mudança foi impulsionada pela crise em que a cidade de Barcelona e sua região metropolitana se encontravam. Um dos fatores que auxiliou na mudança e na implementação do planejamento estratégico da cidade foi, como já ressaltado, a transição da ditadura para a democracia, entre os anos de 1975 e 1979 e os primeiros anos do governo local eleito democraticamente em 1979. A continuidade do mesmo partido no poder, nas eleições posteriores de 1983, 1987, 1991, 1995, 1999, 2003 e 2007, também possibilitou a continuidade das mudanças implementadas. Logo, a velocidade com a que 
as mudanças se deram pode ser explicada por uma coincidência de fatores estruturais e conjunturais. $\mathrm{O}$ primeiro fator estrutural descrito por Borja (1995) é o fato da economia industrial estar em crise, mas Barcelona tinha uma base diversificada de mão-de-obra qualificada. Outro fator estrutural importante destacado pelo autor era a estrutura social, que apesar de desigual, estava de alguma forma organizada e articulada. $\mathrm{O}$ último fator estrutural eram as possibilidades oferecidas em termos de estruturação de uma cultura urbana comum (BORJA, 1995).

Os fatores conjunturais relatados por Borja (1995) se dividem em três: O primeiro era a reação econômica européia e consequientemente a espanhola, que se deu em parte por meio da integração da Espanha no mercado comum europeu na década de 80; O segundo fator conjuntural foi a eleição do Governo Socialista no âmbito federal, em 1982, que se mostrou mais aberto a cooperar com o poder local e regional do que os Governos Centralistas anteriormente no poder, desde o fim da Guerra Civil Espanhola em 1939; O terceiro fator conjuntural foi o resultado eleitoral de 1979, confirmado em 1983, 1987 e 1991 com a maioria da esquerda e apoio do centro, ou seja, a estabilidade política (BORJA, 1995).

Além disso, de acordo com Marshall (2000), os políticos que governam a cidade acreditam no processo de planificação de Barcelona, bem como têm a convicção de que esse processo se tornou uma parte essencial da governança mais ampla da cidade. Logo, com a continuação dos socialistas no município, parece provável que o planejamento estratégico permanecerá como parte da cidade e da governança da máquina Estatal (MARSAHALL, 2000).

Essa estabilidade política pode ter também facilitado o denominado protagonismo da cidade e a geração de consenso, em torno de um projeto comum de cidade e de uma visão de futuro que envolvesse os agentes urbanos, tendo como base a participação, pontos-chave na metodologia de planificação desenvolvida dentro dos planos estratégicos da cidade e posteriormente de sua região metropolitana, gerando assim um ciclo de planificação continuado. Para facilitar a compreensão do ciclo de planificação, dividiu-se esse ciclo em seis etapas, contudo, como o próprio nome do processo sugere, trata-se de um ciclo em que a ordem das etapas não é importante, o que interessa é o processo contínuo de planificação, que foi alavancado pelos contextos histórico, administrativo e político da cidade de Barcelona.

Na primeira etapa do ciclo de planejamento, há a implementação dos mecanismos institucionais. A partir daí, passa-se à segunda etapa: a elaboração do diagnóstico, da qual se destacam as potencialidades e as fraquezas da cidade e, posteriormente, de sua região metropolitana. Na terceira etapa - de estudos ou para atualização ou elaboração do plano, iniciam-se as análises do diagnóstico para elaborar a visão de futuro, os objetivos e os projetos do plano. Depois, na quarta etapa, passa-se para a elaboração do documento do plano estratégico em si, com a definição de projetos, objetivos e indicadores e metas temporais para cada objetivo e projeto, que serão submetidos ao conselho geral que aprovará ou não o que foi redigido. Passa-se, então, para a quinta fase a implementação do plano estratégico. Após a implementação, chega-se à sexta etapa - a avaliação das ações implementadas. A partir da sexta etapa, inicia-se novamente o processo, gerando assim o que definimos como ciclo da planificação continuado. Tendo este ciclo como base, observamos que os quatro planos estratégicos de Barcelona possuíam uma visão competitiva da cidade e pretendiam uma inserção no contexto regional, na Comunidade Econômica Européia e no mercado internacional globalizado, tendo para isto uma lógica e uma continuidade.

Assim sendo, a metodologia, assim como a estrutura dos mecanismos institucionais, foi mantida do primeiro até o terceiro plano. E como pode se observar - na tabela anterior, o quarto plano deixou de ser apenas para cidade e passou a englobar toda a região metropolitana de Barcelona, isto é, 36 municípios (ASSOCIACIÓ PLA ESTRATÉGIC BARCELONA 2000, 2006i).

Tendo todos estes condicionantes como base, a seguir, pode-se observar a metodologia, a coleta e análise de dados que foram realizadas, para cumprir o objetivo central deste artigo, analisar os mecanismos de gestão dos 
planejamentos estratégicos da experiência de Barcelona, verificando quais os condicionantes que permitiram a adoção e a perpetuação do método de planificação na referida cidade.

\section{Metodologia e Coleta de Dados:}

De acordo com a taxonomia de Vergara (2004), esta pesquisa é uma análise exploratória dos contextos políticos, sociais e históricos que impulsionaram planos instituídos na cidade de Barcelona. Seguindo a mesma taxonomia, esta é uma pesquisa bibliográfica e documental. Bibliográfica, pois foram utilizados materiais publicados em diferentes fontes de referência. Documental, devido ao fato de estar se utilizando documentos pesquisados nos órgãos públicos das duas cidades relativos à construção do objeto de estudo.

Trata-se também de uma pesquisa de campo, pois se realizaram 12 entrevistas semi-estruturadas com agentes envolvidos na concepção e na gestão dos planos catalães, nos quais a seleção dos sujeitos se deu pelo critério de acessibilidade e de relevância destes agentes no processo de planificação, sendo assim foram entrevistados:

- O Senhor Juan Campreciós, coordenador do Plano Estratégico de Barcelona. A entrevista auxiliou na construção de uma visão geral dos planos estratégicos de Barcelona, história dos planos, metodologia, funcionamento, estrutura administrativa e executiva das atividades desenvolvidas pelo plano e os resultados alcançados no decorrer de todo processo.

- A Professora Doutora Mireia Belil, professora universitária e pesquisadora, que desenvolve estudos sobre a área metropolitana de Barcelona na Fundació Fòrun Universal de les Cultures, já participou do plano estratégico de Barcelona em suas primeiras versões. A entrevista contribuiu com uma visão geral dos planos estratégicos de Barcelona, história dos planos, metodologia, funcionamento. Contudo, a Professora possui uma visão crítica dos planos e dos resultados alcançados por ele.

- O Senhor Joan Playà, prefeito de Castellbisbal, município da região metropolitana de Barcelona que faz parte do Plano Estratégico. O entrevistado contribuiu com uma visão de um agente diretamente envolvido no processo, avaliou de pontos positivos e negativos dos planos e de seus mecanismos de gestão e de concertação, além de sua ligação com entidades como a Mancomunitat de Municipis de l'Àrea Metropolitana de Barcelona. A visão de um município pequeno, como Castellbisbal, a respeito do plano, mostra como funciona o processo de concertação dos agentes e o que leva os prefeitos a participarem de todo processo. $\mathrm{O}$ entrevistado mostrou o que move os prefeitos a participarem de um processo liderado por Barcelona.

- O Professor Doutor Manuel de Forn, professor universitário e consultor, participou da elaboração dos planos estratégicos de Barcelona. A entrevista auxiliou na construção de uma visão geral dos planos estratégicos de Barcelona, além da história, metodologia, funcionamento, estrutura administrativa e executiva das atividades desenvolvidas dos planos de Barcelona.

- O Senhor Josep Carreras, Chefe del Servei d'Informació i Estudis Territorials de la Mancomunitat de Municipis de l'Àrea Metropolitana de Barcelona, instituição que possui ligação e caminha paralelamente ao Plano Estratégico de Barcelona, foi o quinto entrevistado em Barcelona. A entrevista mostrou a visão técnica do processo de planejamento da região metropolitana e serviu como base para entrevista posterior com o Senhor Jaume Vendrell.

- O Senhor Jaume Vendrell, Gerente da Mancomunitat de Municipis de l'Àrea Metropolitana de Barcelona, instituição que possui ligação e caminha paralelamente ao Plano Estratégico de Barcelona, mostrou a ligação do plano estratégico de Barcelona com entidades como a Mancomunitat de Municipis de l'Àrea Metropolitana de Barcelona, a tradição histórica de planejamento da região e cultura dos municípios em se unirem para realizar o planejamento territorial conjuntamente. Durante a entrevista, foi possível mapear como se realiza a implementação de políticas públicas que agrupam diferentes municípios e agentes na região metropolitana de Barcelona. 
- O Senhor Jose Manuel Jurado, responsável de Medi Ambient de la Comissió Obrera Nacional de Catalunya, sindicato que participa dos grupos de trabalho do Plano Estratégico de Barcelona. $\mathrm{O}$ entrevistado mostrou como algumas instituições presentes na metropolitana de Barcelona participam do plano estratégico por meio de grupos de trabalho, dando uma visão sindical sobre o plano. Assim como, descreveu o que leva a associações como a Comissió Obrera Nacional de Catalunya (CCOO) a participarem do plano, que interesses têm, a quem representam e o que ganham com esta participação. Destacou a parte do plano que se relaciona ao meio ambiente, as estratégias que estão ligadas a este tema e sua conexão com o mundo sindical.

- O Senhor Jordi López, Diretor Geral da LocalRet, instituição que participa dos grupos de trabalho do Plano Estratégico de Barcelona. O entrevistado mostrou, mais uma vez, como algumas instituições presentes na metropolitana de Barcelona participam do plano estratégico por meio de grupos de trabalho. Destacou estratégias ligadas a telecomunicações e a importância do setor para o desenvolvimento das grandes metrópoles. Corroborou alguns pontos da entrevista anterior com o Senhor Jose Manuel Jurado da CCOO.

- O Senhor Carlos Martinez, responsável, dentre outras atribuições, por acompanhar o Plano Estratégico Metropolitano de Barcelona na Comissió Obrera Nacional de Catalunya, instituição que participa dos grupos de trabalho do referido plano. O Entrevistado mostrou especificamente como a CCOO participa do plano estratégico por meio de grupos de trabalho, complementou a visão sindical sobre o plano, conferida pela entrevista realizada com Senhor Manuel Jurado da mesma instituição. Descreveu mais detalhadamente, e com exemplos práticos, o que leva uma associação como a Comissió Obrera Nacional de Catalunya (CCOO) a participar do plano e o que ganha com esta participação. Destacou a parte do plano que se relaciona ao transporte público e à negociação com a patronal, às estratégias que estão ligadas a este tema e sua conexão com o mundo sindical.

- O Professor Doutor Juli Ponce Sole, professor titular de direito administrativo da Faculdade de Direito da Universidade de Barcelona, especialista em Direito Urbanístico e diretor da Escola de Governo da Catalunha. O professor elucidou especificamente como funcionam os grupos de trabalho do Plano Estratégico, como são feitos os convites pelo escritório do plano estratégico metropolitano de Barcelona para realização de estudos, e o que é feito com esses estudos após suas publicações. Detalhou o dia-a-dia da coordenação de um grupo de trabalho. Além disso, apontou as questões jurídicas que envolvem a região metropolitana de Barcelona do ponto de vista histórico e administrativo.

- O Senhor Juan Martinez, Presidente da CONFAV (Confederación de Asociaciones de Vecinos). O entrevistado também destacou especificamente como funcionam os grupos de trabalho do Plano Estratégico, como são feitos os convites pelo escritório do plano estratégico metropolitano de Barcelona. Detalhou como se dá a participação pública no plano de Barcelona. Além disso, apontou as questões relevantes sobre como são organizadas as reuniões dos planos e como são discutidas questões ligadas à implementação das políticas públicas após as estratégias a serem delineadas.

- O Professor Doutor Juan Subirats, que fez parte de um grupo de intelectuais responsável pela análise da reforma do Estado Espanhol e que fazia parte dos precursores da metodologia utilizada no plano catalão. A entrevista elucidou alguns aspectos da teoria do autor, assim como mostrou as similaridades da teoria com a metodologia de planificação catalã. Apontou uma alternativa para construção de uma rede para estabelecer a governança metropolitana na região metropolitana de Barcelona.

Objetivou-se realizar por meio destas 12 entrevistas e do método de análise escolhido a correspondência entre as estruturas semânticas, lingüísticas ou sociológicas dos enunciados observados no decorrer da leitura das transcrições. Isso é possível, pois o método de análise de conteúdo configura-se como um conjunto de técnicas com procedimentos sistematizados e objetivados, estruturados para descrever os conteúdos das mensagens analisadas (BARDIN, 1977). 
Os dados coletados, tanto em documentos como em entrevistas (que devem ser preferencialmente abertas ou semi-estruturadas), são analisados de acordo com categorias preestabelecidas, ou não, que dependem do tipo de grade que se opta em trabalhar e da unidade de análise estabelecida pelo pesquisador (parágrafo, frase, expressão ou palavra). Após a categorização do material e de sua inserção na grade, procede-se à análise de conteúdo adotando, para tanto, procedimentos que vão desde estatísticos a interpretativos, ou ambos (VERGARA, 2005).

As grades podem ser de três tipos: aberta, fechada ou mista. Neste artigo, optou-se por uma grade aberta, na qual as categorias não são definidas preliminarmente. Ao fim da pesquisa, estabelece-se a grade categórica final levando-se em consideração os arranjos feitos no decorrer do trabalho (VERGARA, 2005). Utilizou-se critério semântico de categorização, no qual cada categoria tem um tema que agrupa elementos de análise. Para ilustrar esta opção, será observado o exemplo dado por Dellagnelo e Silva (2005): os elementos que refletem ansiedade serão agrupados em uma categoria ansiedade; os elementos que refletem valores individuais serão agrupados em uma categoria individualismo (DELLAGNELO; SILVA; 2005:112).

Dentro desta análise, procurou-se desvendar a visão dos agentes envolvidos na concepção dos planos de Barcelona com o objetivo de observar o que sustentou ao longo do tempo o seu processo de planificação e de que forma este processo se configurou.

\section{Análise dos Dados:}

Dentro desta pesquisa, no decorrer da análise do material coletado, após a leitura e interpretação das transcrições das 12 entrevistas realizadas em campo, diferentes elementos emergiram e se repetiram. Estes elementos apontaram para a criação de diferentes categorias. Tendo como base o desenho prévio das categorias e os elementos que apontaram para sua criação, retomou-se a teoria utilizada para análise dos processos de planificação das duas cidades, a fim de verificar se a interpretação dos dados estava de acordo com o marco teórico utilizado. Após a verificação, agruparam-se os elementos observados em quatro grandes categorias, sendo que a categoria instituições foi dividida em três subcategorias, que juntas definem a categoria mais geral que as deriva, conforme se pode observar abaixo:

- Categoria 1 - Personalismo Político: definido como as relações pessoais que se sobrepõem às relações institucionais.

- Categoria 2 - Instituições: se subdivide em três subcategorias:

- Categoria 2.1. - Porosidade institucional: definida como a sinergia, presença de laços entre o Estado e a sociedade. Esta porosidade pode criar as bases para a constituição de capital social, influenciando positivamente o desempenho institucional.

- Categoria 2.2. - Responsividade institucional: definida como a capacidade das instituições em responderem demandas advindas da sociedade.

- Categoria 2.3. - Adaptabilidade institucional: definida como a capacidade das instituições em se adaptarem às mudanças dos cenários no qual elas se inserem.

- Categoria 3 - Agenda Política: processo de articulação de agentes com objetivos comuns em torno de uma política pública estruturada.

- Categoria 4 - Dotes socioculturais: definida como o capital social acumulado ao longo do tempo por meio do exercício cívico.

Após verificação das categorias que auxiliaram a análise do material coletado, com a ajuda do software de análise de conteúdo ATLAS ti, visando consolidar as categorias principais que foram extraídas da leitura e da interpretação das entrevistas, e que corresponderão à espinha dorsal da conclusão da tese, foi possível estabelecer a relação entre as categorias da análise de conteúdo, conforme figura 01 abaixo. 
Figura 01- Relações Entre Categorias da Análise de Conteúdo de Barcelona

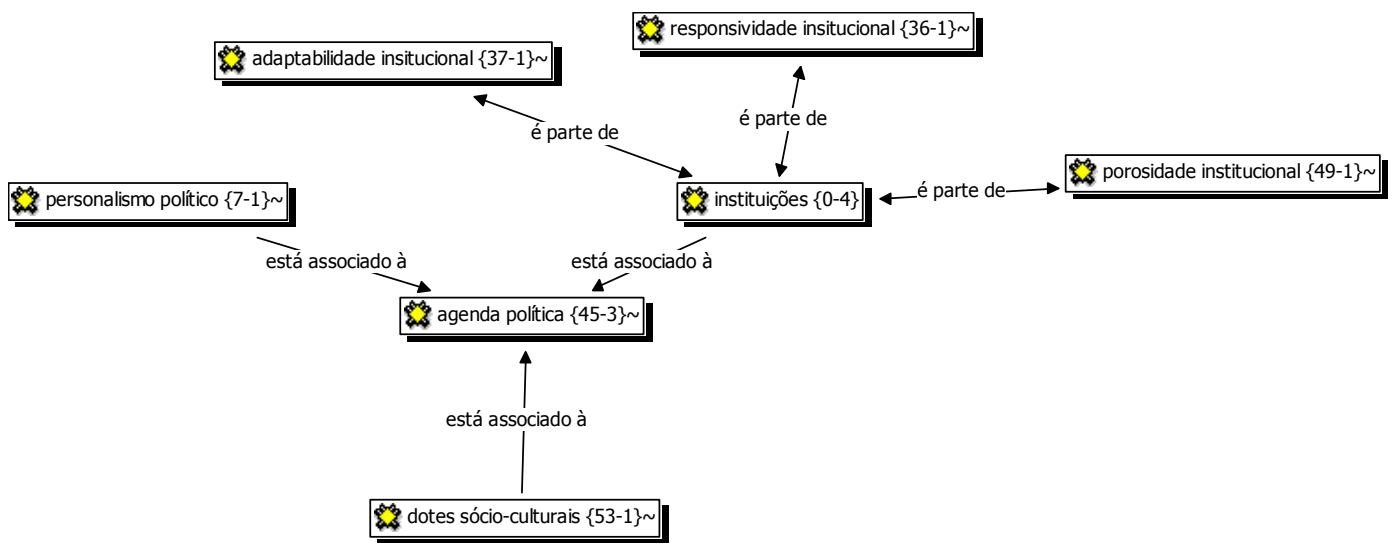

Por meio da análise das relações estabelecidas entre as categorias e subcategorias, observou-se que não há citações diretas para a categoria instituições, mas que as subcategorias responsividade, porosidade e adaptabilidade fazem parte da categoria. Em conjunto, essas três subcategorias puderam ser utilizadas para analisar de que forma tais características institucionais contribuíram para a perpetuação dos processos de planificação nas duas cidades. A categoria instituições, em conjunto com as outras duas categorias, dotes socioculturais e personalismo político, está associada à categoria agenda política. Assim, pôde-se observar qual categoria influenciou mais fortemente na agenda política, mantendo, ou não, um processo de articulação de agentes com objetivos comuns em torno de uma política pública estruturada.

Estruturada esta rede de relacionamento entre as categorias e subcategorias, foi possível saber quais foram os condicionantes que permitiram a adoção e a perpetuação do método de planificação das duas cidades, segundo a percepção dos entrevistados. Deve-se ressaltar que as categorias e subcategorias que emergiram da coleta de dados realizada por meio de entrevistas, com agentes envolvidos direta e indiretamente no processo de planificação das duas cidades, referem-se a condicionantes históricos (percebidos pela categoria dotes socioculturais), condicionantes políticos (captados pela categoria personalismo político) e a condicionantes institucionais (coletados por meio da categoria instituições e suas subcategorias). Todos esses condicionantes estavam associados à agenda política, estruturando ou não um ciclo de planificação continuado (percebido por meio da presença da categoria agenda política). Pode-se verificar a estrutura de análise na figura 2 abaixo. 
Figura 2 - Estrutura da Análise dos Dados

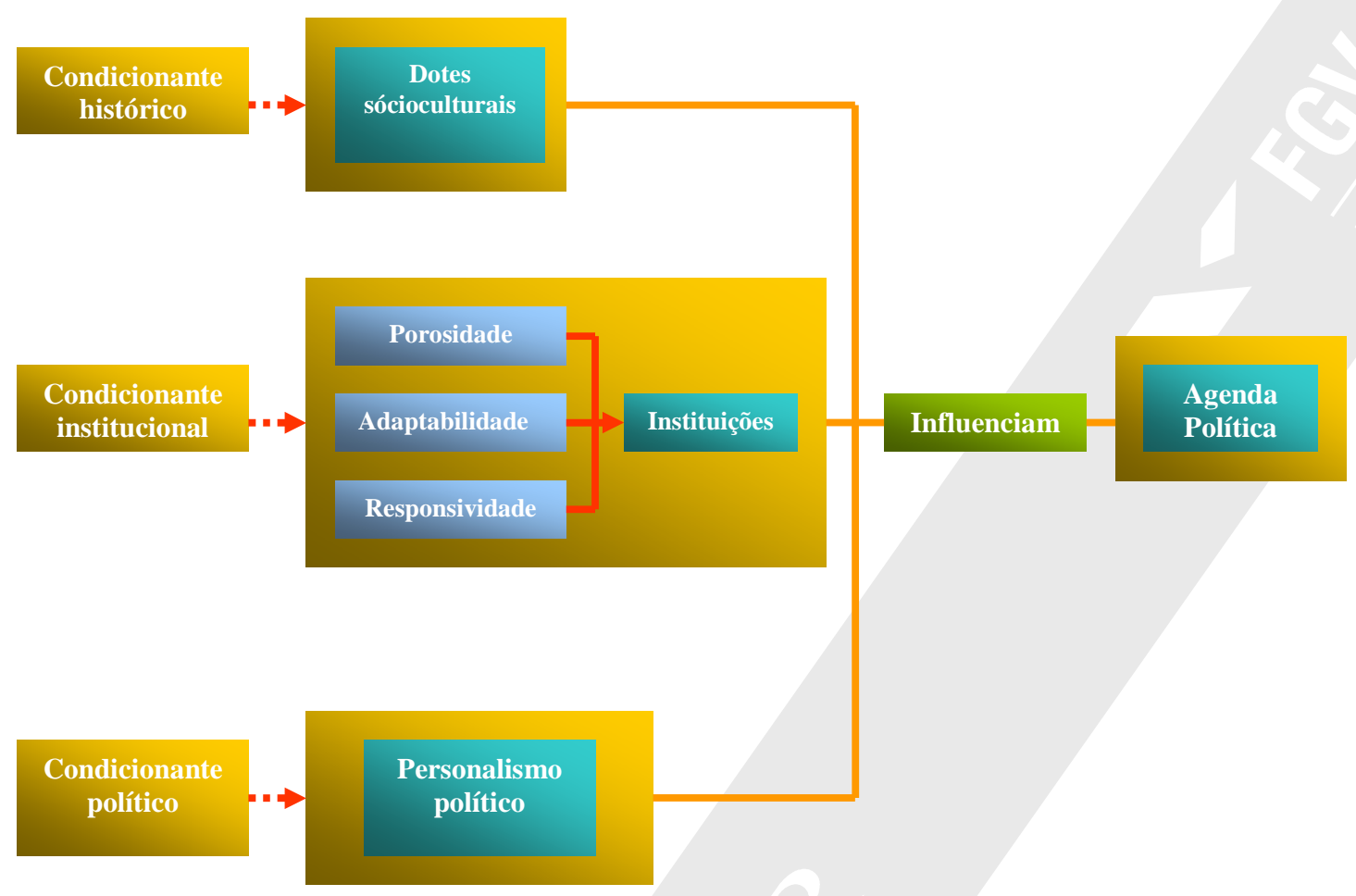

Tanto o condicionante político como o condicionante institucional sofrem influências de fatores históricos. No entanto, para efeito de análise e para que a observação dos dados coletados ficasse mais clara, metodologicamente, optou-se por observar apenas um fator histórico, os dotes socioculturais, e separar este condicionante histórico em uma categoria específica. A referida opção possibilitou que as conclusões finais desta tese tivessem uma maior objetividade.

\section{Tabela 01 - Cenário Complexo de Barcelona}

\begin{tabular}{ccccccc}
\hline Entrevistados & $\begin{array}{c}\text { Adaptabilidade } \\
\text { institucional }\end{array}$ & $\begin{array}{c}\text { Agenda } \\
\text { política }\end{array}$ & $\begin{array}{c}\text { Dotes } \\
\text { socioculturais }\end{array}$ & $\begin{array}{c}\text { Personalismo } \\
\text { político }\end{array}$ & $\begin{array}{c}\text { Porosidade } \\
\text { institucional }\end{array}$ & $\begin{array}{c}\text { Responsividade } \\
\text { institucional }\end{array}$ \\
\hline B1 & 5 & 6 & 11 & 0 & 8 & 13 \\
\hline B2 & 1 & 3 & 0 & 0 & 7 & 4 \\
\hline B3 & 6 & 6 & 4 & 0 & 8 & 2 \\
\hline B4 & 1 & 8 & 11 & 0 & 6 & 2 \\
\hline B5 & 2 & 8 & 4 & 0 & 2 & 7 \\
\hline B6 & 6 & 0 & 1 & 3 & 1 & 2 \\
\hline B7 & 2 & 5 & 0 & 1 & 6 & 1 \\
\hline B8 & 2 & 2 & 2 & 0 & 4 & 2 \\
\hline B9 & 2 & 2 & 4 & 2 & 4 & 1 \\
\hline B10 & 3 & 1 & 7 & 0 & 1 & 0 \\
\hline B11 & 3 & 0 & 6 & 0 & 1 & 36 \\
\hline B12 & 4 & 4 & 3 & 1 & 49 & \\
\hline TOTAL & 37 & 45 & 53 & 7 & & 2 \\
\hline
\end{tabular}


Por meio da análise das frequiências das categorias no cenário complexo de Barcelona, pode-se observar que a agenda política pode ter estruturado um ciclo de planificação continuado, o que, em tese, pode ser observado pelo número de citações a este categoria, 45 no total. Percebe-se também que a princípio há um certo equilíbrio entre as subcategorias da categoria instituições. Isso porque ao mesmo tempo em as instituições são muito porosas (49 citações), elas são responsivas (36 citações) e adaptáveis (37 citações). Além disso, na soma do número de citações destas subcategorias que compõem a categoria instituições se concretizam em um total de 112 citações, o que faz com que a categoria instituições seja a mais associada à categoria agenda política. Assim, por meio da análise das relações estabelecidas entre as categorias e subcategorias, observou-se que não há citações diretas para a categoria instituições, mas que as subcategorias responsividade, porosidade e adaptabilidade, que fazem parte da categoria, em conjunto puderam ser utilizadas para analisar e observar que tais características institucionais contribuíram fortemente para a perpetuação dos processos de planificação nas duas cidades.

Em tese, esta constatação pode levar a crer que as instituições catalãs são estruturadas de uma maneira que se consegue levar adiante políticas públicas, de forma a dar continuidade à agenda política, articulando agentes com objetivos comuns em torno de uma política pública estruturada e por conseguinte mantendo o ciclo de planificação, independentemente de quem esteja no poder, tendo em vista também que o personalismo político é mínimo, com apenas 7 citações.

Tudo isso pode ser melhor entendido por meio do gráfico 1 abaixo, no qual se encontram as distribuições proporcionais das categorias e subcategorias de Barcelona. Neste gráfico, é possível notar que apesar da categoria dotes socioculturais ter um peso maior em relação às outras categorias separadamente, com um total de $23 \%$ das citações, se observarmos as subcategorias da categoria instituições em conjunto, essa relação muda. Há um peso maior das características institucionais presentes no processo de planificação de Barcelona, observando-se em conjunto as subcategorias porosidade institucional (20\% das citações), responsividade institucional (16\% das citações) e adaptabilidade institucional (16\% das citações), o que faz com que a categoria instituições (com todas as suas subcategorias em conjunto) possua maior influência na agenda política.

Gráfico 1 - Distribuições Proporcionais das Categorias e Subcategorias de Barcelona 


\section{Conclusão:}

No caso de Barcelona, o condicionante que mais influenciou na adoção e a perpetuação do método de planificação em Barcelona foi o condicionante institucional, mantendo um certo equilíbrio entre os elementos relacionados: a porosidade, adaptabilidade e responsividade das instituições catalães. Com base na preponderância deste condicionante, pode-se supostamente concluir-se que as instituições catalãs são estruturadas de uma maneira em que conseguem levar adiante políticas públicas de forma a dar continuidade à agenda política. Assim, alcançando objetivo central e respondendo a pergunta delineada neste artigo, concluise que foi o condicionante institucional que mais influenciou na adoção e perpetuação do processo de planificação da cidade de Barcelona, estabelecendo assim ciclo de planificação continuado e uma agenda política, isto é, permitindo a criação e a manutenção de um processo de articulação de agentes com objetivos comuns em torno de uma política pública estruturada.

Esta conclusão nos permite observar que a metodologia catalã se insere em um cenário complexo em que as instituições têm um peso forte no processo de elaboração de políticas públicas participativas e onde o Estado, de acordo com a percepção dos agentes envolvidos no processo de planificação de Barcelona, conseguiu, ao longo ao tempo, estabelecer instituições porosas, responsivas e adaptáveis, estabelecendo assim um ciclo de planificação continuado, que é facilitado pelos contextos político, administrativo e histórico próprios da referida região.

Além disso, a mesma conclusão aponta para o fato de que a metodologia catalã, tão embasada no cenário complexo ao qual se insere, na qual o principal condicionante é o institucional, deve ser adaptada quando aplicada em um cenário diferente. Essa adaptação poderia em tese permitir o estabelecimento de uma agenda política estruturada em torno de um ciclo de planificação continuado nas diferentes regiões que, por meio da disseminação do método por diferentes agências internacionais como o BID, receberam a referida metodologia. Contudo, as adaptações concernentes a esta metodologia, ou à criação de uma nova metodologia, não fazem parte do escopo deste artigo, ficando como sugestão para pesquisas futuras.

Com base no que foi acima delineado, seria necessário observar os resultados da metodologia nas diferentes cidades que a adotaram como parte de seus mecanismos de gestão, o que enriqueceria a pesquisa e poderia corroborar os resultados preliminarmente alcançados. Em relação à cidade de Barcelona, o estudo desenvolvido mostra que as instituições da capital catalã, ao longo do tempo, por conta dos condicionantes explorados no artigo, se desenvolveram e se fortaleceram de forma a levar adiante políticas públicas de longo prazo independentemente de quem está no poder. É claro que a permanência de um único partido durante vinte anos na liderança da prefeitura tem um peso importante no contexto analisado. Contudo, a presença de instituições autônomas e o fato do plano ser um organismo fora da prefeitura, com estatuto próprio e autonomia diretiva também mostra a força das instituições e sua capacidade de organização independente de fatores puramente políticos. 


\section{Referencias}

AJUNTAMENT DE BARCELONA. Gobierno y Gestión de la Ciudad: Una experiencia de modenización municipal. Barcelona: Ajuntament de Barcelona e Diaz Santos, 1999.

AJUNTAMENT DE BARCELONA. www.bcn.es/alcalde, acesso em março de 2007.

ASSOCIACIÓ PLA ESTRATÉGIC BARCELONA 2000. I Plan Estratégico Metropolitano de Barcelona. Barcelona: Associació Pla Estatégic Barcelona 2000, 2003. Disponível também em: http://www.bcn2000.es/ca-es/default_ca_es.aspx, acesso em novembro de 2006.

BARDIN, Laurence. Análise de Conteúdo. Lisboa: Edições 70, 1977.

BORJA, J. La Transformación Urbana de Barcelona: Velocidad y Globalizad. In: BORJA, J (org.).Barcelona. Un Modelo de Transformación Urbana. Quito: Oficina Regional para América Latina y el Caribe, 1995, pp. 01-34.

DELLAGNEO, Eloise Helena Livramento e SILVA, Rosimeri Carvalho. Análise de conteúdo e sua aplicação em pesquisa na administração. In: VIEIRA, Marcelo Milano Falcão e ZOUAIN, Deborah Moraes (orgs.). Pesquisa Qualitativa em Administração: Teoria e Prática. Rio de Janeiro: FGV, 2005, 97-118.

ESPANHA. Constitución Española, 1978.

. Ley Orgânica 5/1985, de 19 de junio, Del Régimen Electoral General, 1985.

EVANS, Peter. Embedded Autonomy. Princeton University Press, 1995.

State-Society synergy: government and social capital in development. Berkeley: University of California,

1997.

GENERALITAT DE CATALUNHA. www.gencat.net, acesso em maio de 2007.

MARSHALL, Tim. Urban Planning and Governance: Is there a Barcelona Model? Internacional Planning Studies, Oxford: Oxford Brookes University, vol.5, no 3, 2000, pp.299-319.

MONCLÚS, Francisco Javier. The Barcelona Model: an original formula? From "reconstruction" to strategic urban projects (1979-2004). Planning Perspectives. Routledge, part of the Taylor \& Francis Group, V. 18, no 4, outubro de 2003, pp. 399421.

PLANO ESTRATÉGICO DE BARCELONA. Disponível em http://www.bcn2000.es/es/default es.aspx. Acesso em janeiro de 2006.

SKOCPOL, Theda; EVANS, Peter e RUESCHEMEYER, Dietrich (org.). Bringing the State Back In. Cambridge University Press, 1985.

SKOCPOL, Theda. Bringing the State Back In: Strategies of Analysis in Current Research. In: SKOCPOL, Theda; EVANS, Peter; RUESCHEMEYER, Dietrich (org.) Bringing the State Back In. Cambridge University Press, 1985, pp.3-35.

SUBIRATS, J. Análise de Políticas y Eficácia de la Administración. Madrid: Instituto Nacional de Administración Publica, 1989. VERGARA, Sylvia Constant. Métodos de Pesquisa em Administração. São Paulo: Atlas, 2005.

Agradecimentos especiais à Coordenação de Aperfeiçoamento de Pessoal de Nível Superior (CAPES), que, por meio do Programa de Doutorado no País com Estágio no Exterior (PDEE), proporcionou a pesquisa de campo realizada em Barcelona. 